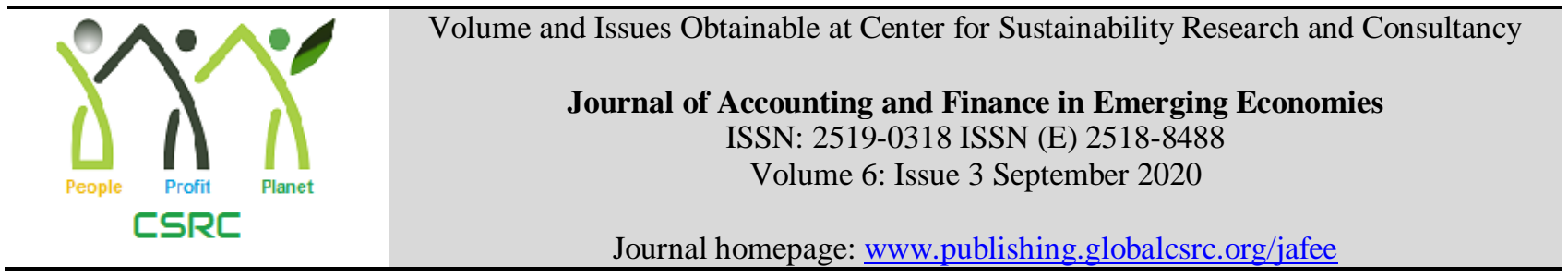

\title{
HR Practices and Employee Retention in the Banking Sector of Pakistan
}

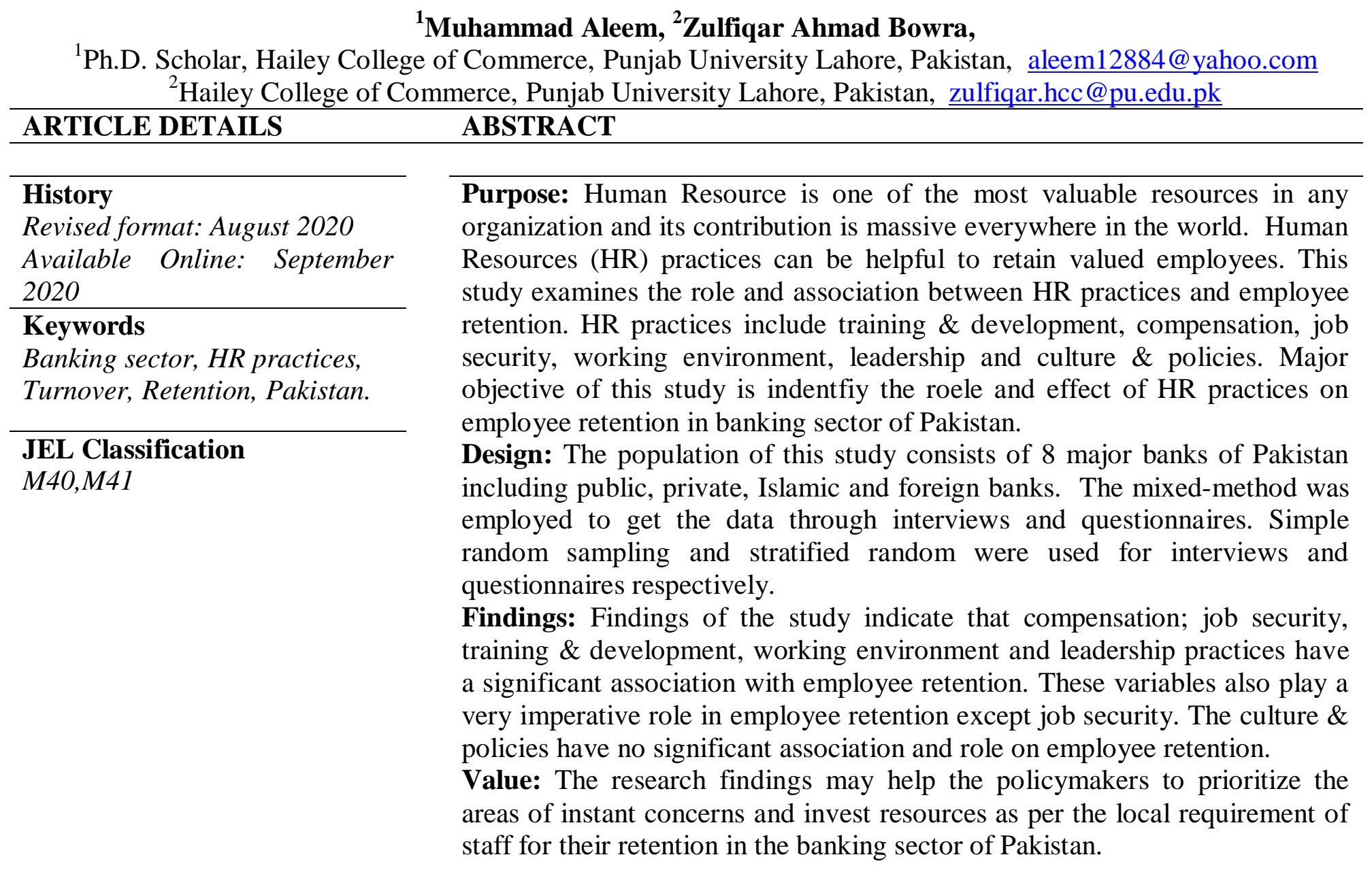

\section{OPEN ACCESS}

(C) 2020 The authors, under a Creative Commons Attribution-NonCommercial 4.0

\section{Corresponding author's email address: aleem12884@yahoo.com}

Recommended citation: Aleem, M., \& Bowra, Z. A. (2020). HR Practices and Employee Retention in the Banking Sector of Pakistan. Journal of Accounting and Finance in Emerging Economies, 6(3), 787-798

\section{Introduction}

Human Resources are the most imperious element in any organization. Although an organization has substantial economic and technological resources, yet it cannot endure without an efficient workforce. The organization can achieve its objectives by improving the performance and productivity of staff by implementing the best HR practices. Therefore in the recent era, many modern organizations invest more in HR to get better and efficient consequences. The retention of employees and building their commitment to the organization always remain a challenge for every organization and manager. Thus, organizations are exerting energies and efforts at their full length for satisfaction and 
retention of staff.

Employee retention has not only become a challenge for the organizations in the current era but also posing a great peril in financial terms as well. To manage this phenomenon is important for all types of organizations especially for the services sector because it has a direct relation with their customers. The turnover impact and pattern would differ from one sector to another but it is more important for the service sector. The turnover should be reduced in all sectors because it curtails productivity and output.

There is a need to develop and implement the comprehensive plan and strategies to attract, develop and retain the staff in the organization for the long term (Shahid, 2017). The quality for customer service is very important in the service sector and bank staff plays a vibrant role to provide quality services to the clients. The manager should take necessary measures for the retention of staff to deliver efficient and consistent quality services to the clients (George \& Zakkariya, 2015). Stavrou-Costea (2005) argues that effective HR practices are the base to retain the employees and finds a significant association between HR practices and employee retention. Abeysekera (2007) states that an organization can reduce employee turnover by implementing the best HR practices.

The banking industry is playing a vibrant role in the economy of Pakistan. The Government of Pakistan is facilitating the foreign investor for motivation and attraction for investment in the banking sector. The multinational banks also flourishing in the country by providing alternative opportunities to experienced staff. Currently, there is a tendency to hire talented/capable and trained employees with professional skills to compete in the market. Bilal et al. (2015) state that turnover is a major problem for all firms especially for the banks and due to competitive pressure it is challenging for the banks to retain brilliant staff. The major objectives of the study are as under.

1. To determine the factors effecting employee retention in the banking sector.

2. To identify an association and role between selected HR practices and employee retention?

\section{Literature Review}

Various evidence is available in the literature that indicates that HRM plays a very vibrant role to raise employee retention in the organization. Many techniques, strategies and methods are available to get competitive advantages in the market and one of the best methods for the organization to implement effective HR practices (Narsimha,2000). Dei Mensah (2014) states that HRM practices are mandatory for the financial sector particularly for the banking sector due to competition and the global financial system. Thus, there is a dire need of a proactive and strategic approach to retain and motivate the employees for a long period.

\subsection{Training \& Development}

The dearth of training \& development practices has a significant effect on staff high intention to leave the firms (Chew, 2004; Shoaib 2009). The staff feels that their strengths and abilities have been increased due to training which contributes positively to employee retention (Waleed, 2011). Ngethe (2013) concludes that in the current competitive and global era, employee retention and productivity can be increased with the help of comprehensive training programs. Neog and Barua (2015) state that if the organization is providing the training and development breaks to the staff, it will increase their retention rate. In light of the above discussions, the following hypothesis can be developed.

H 1: There is a significant relationship and role between Training \& development and employee retention in the banking sector of Pakistan.

\subsection{Compensation Practices}

The major objective of the compensation practices is to attract, motivate and retain the staff for the success and improvement in productivity of the firm (Armstrong, 2010). Attractive remuneration is one of the major and basic factors for employee retention because it fulfills the material and monetary desires of the staff to maintain their standard of living and status (Shoaib et al., 2009). Kotachachu (2010) concludes from his study, the turnover rate of staff is high when the compensation is less than the market and other competing firms in the industry. One of the basic reasons regarding lower retention level of staff is lower incentives, allowances and salary offered by the firm(Chikaji et al.,2016). In light of the above discussions, the following hypothesis can be developed.

H 2: There is a strong relationship and role between compensation and employee retention in the banking sector of 


\section{Pakistan.}

\subsection{Job Security}

The job security of staff in the public and private sectors including the banking sector has a significant and positive association with employee retention (Samuel and Chipunza, 2009). The continuity and security of work is a significant and major contributor to staff retention and satisfaction (Milne, 2007). The staff will be more committed and motivated with the work in case of job security. The research indicates that job security is a major and vital factor to enhance employee retention (Alzayed and Murshid, 2017). It is the need of the current era because some employees cogitate it more imperative than compensation and promotion. In light of the above discussion, the following hypothesis can be developed.

H 3: There is significant relationship and role between job security and employee retention in the banking sector of Pakistan.

\subsection{Leadership}

Leadership is very important because the leader's behaviour can build or ruin the organization. Taylor (2004) posits that the firms should not depend on the HR department to resolve the issue of staff retention rather this obligation should be given to the leaders/managers for its proper and easy solution. Paille et al., (2013) state in their study, if the staff has confidence on the supervisor and also has support from him then the retention rate of staff is very high and vice versa. Nwokocha and Iheriohanma (2015) conclude from their study, staff performance and retention could be enlarged with the support of appropriate leadership practices. The authors also stated that leadership is also helpful for appropriate business strategies to escalate employee morale and motivation. The leadership practices are important and main factors to decide whether staff will leave or stay in the firms (Azeez, 2017). In light of the above discussions, the following hypothesis can be developed.

H 4: There is significant relationship and role between leadership and employee retention in the banking sector of Pakistan.

\subsection{Working Environment}

The working environment is one of the major contributors to employee intention to stay for the long term in the organization (George \& Jones 2008). Neog and Barua (2015) argue that staff attitudes are positive when the working environment is good and there is a strong relationship between employees' retention and working environment. The organization should build such kind of environment, which will fulfill the staff's future and present needs. The employees are so comfortable in the environment, they do not leave the firm even alternative job opportunity is available (Winterton, 2011). Irshad (2009) finds that the working environment is one of the main factors for staff retention and many employees leave the firm due to a poor working environment. In light of the above discussions, the following hypothesis can be developed.

H 5: There is significant relationship and role of Working Environment on employee retention in the banking sector of Pakistan.

\subsection{Organizational Culture}

The employees will stay for a long period with those organizations where they perceive that there is a positive and good which is fit with the employees' behaviour, attitudes, orientation and interest (DiPietro and Milman, 2004). According to Zhao et al., (2007) culture is more imperative than reward and salary because if the staff are comfortable in the culture, it will attract to stay for a long period in the firm. The culture of the organization is an important factor to increase staff retention, performance and adaptability (Chia, Lee, et al., 2014). The culture of an organization is the binding stick to minimize the gap between management and employees. In favourable culture, the staff feels that the organization is their second home. On the basis of the above discussions, the following hypothesis can be developed.

H 6: There is significant relationship and role between organizational culture \& policies and employee retention in the banking sector of Pakistan.

\subsection{Schematic diagram}

On the basis of the literature review, the following schematic diagram is developed. HR practices are divided into two sets i.e. HR and organizational factors. The reason to distinguish between HR and organizational factors is to offer 
greater clarity between management and organizational related activities and shreds of evidence are available in support of this concept (Chew, 2004; Ashraf \& Joarder 2012).

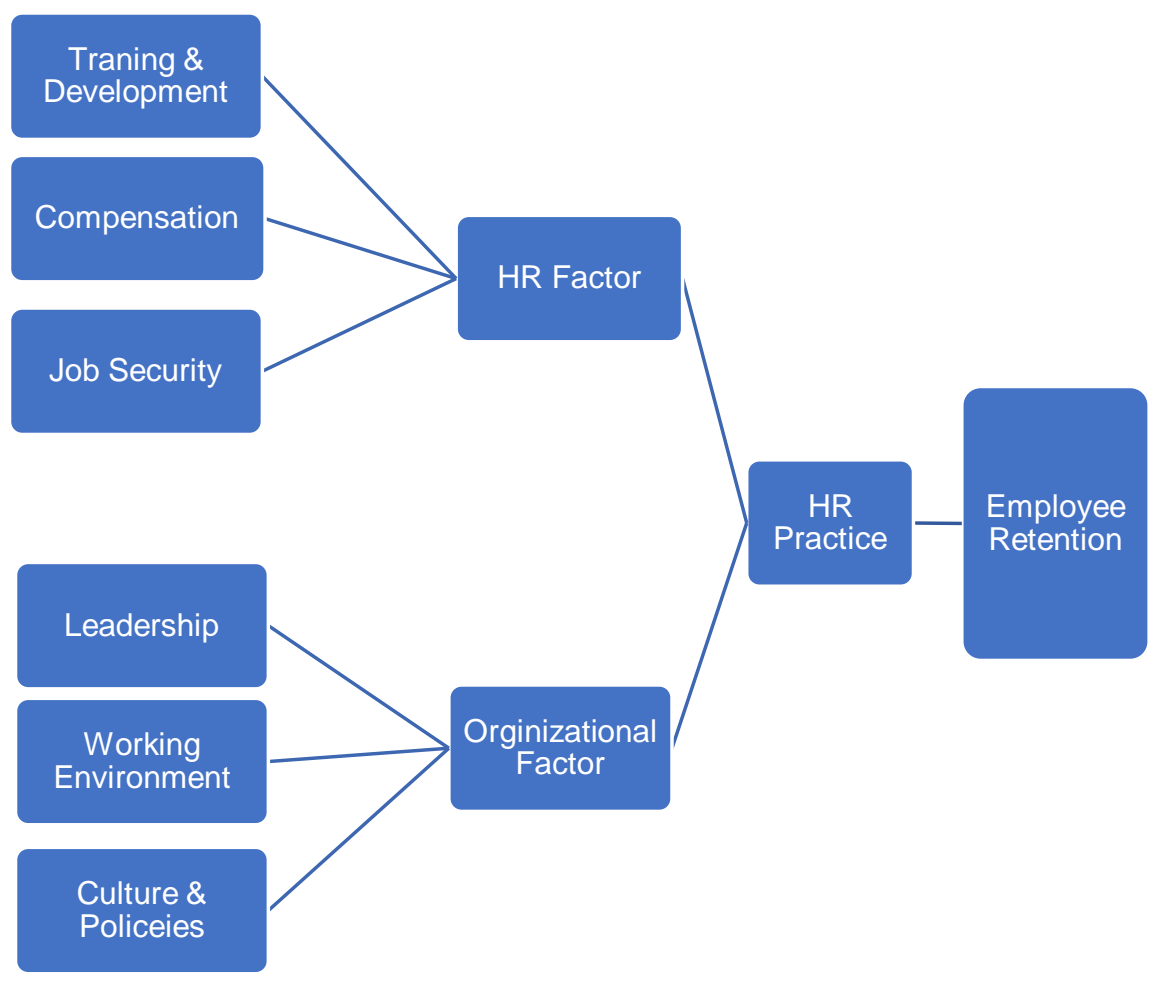

\section{Research Design}

Figure 1: Schematic Diagram

The data is collected with the help of a mixed-method approach to find out the role of HR and organizational factors with employee retention in the banking sector of Pakistan. This approach is used for a better understanding of the issue because it is a better technique when one method is not adequate to address the problem efficiently and effectively (Creswell, 2008).

The population of this study entails 8 major banks of the Pakistani banking sector including public, private, Islamic and foreign banks. Two banks are selected from each sector based on assets worth and data is collected from the staff of HBL, UBL, NBP, Punjab, Meezan, Albarka, SCB and samba bank.

For the qualitative study, interviews are taken from $24 \mathrm{HR}$ managers including 3 mangers from each bank on the basis of the purposive sampling method. For the questionnaires, multi-stage sampling was used. The questionnaire was adopted which had already been used by many researchers. The sample size was 480 respondents by selecting 60 respondents from each institution based on stratified random sampling. The strata based on designation, job status and institution. Simple random sampling was used on the second stage. Pilot testing was also made. The reliability test was conducted by using the value of Cronbach alpha which was greater than 0.7 of each variable which indicates it was reasonable and consistent. The response rate was $79 \%$.

For qualitative analysis, nodes and themes were used and for quantitative analysis factor analysis, descriptive statistics, correlation, reliabilities, multiple Regression were used. The NVivo, MS excel, SPSS 20.0 (software) were used for data analysis.

\subsection{Qualitative Analysis}

The brief finding of the qualitative analysis is as under.

The interview questions are asked from the HR managers regarding training activities and its effect on staff retention. 
The respondents state that training provides the basic knowledge to the staff regarding job requirements, organizational rules \& regulation to perform work efficiently. The bank is spending a massive amount on training/ development practices on an annual basis. The managers of the public and foreign banks responded that training \& development facilities are regular features in their bank. The retention rate of foreign bank staff is high because the training facilities in this bank are very comprehensive and proper. In the public sector banks, at the beginning of the year, the program of the training is being issued to all the branches. The bank also offered the facility of the good food, a five-star hotel, and a prominent scholar for delivering the lecture in the training session. It is concluded that training $\&$ development play a very imperative role in employee retention. The major role of training $\&$ development is given below in figure 2 .

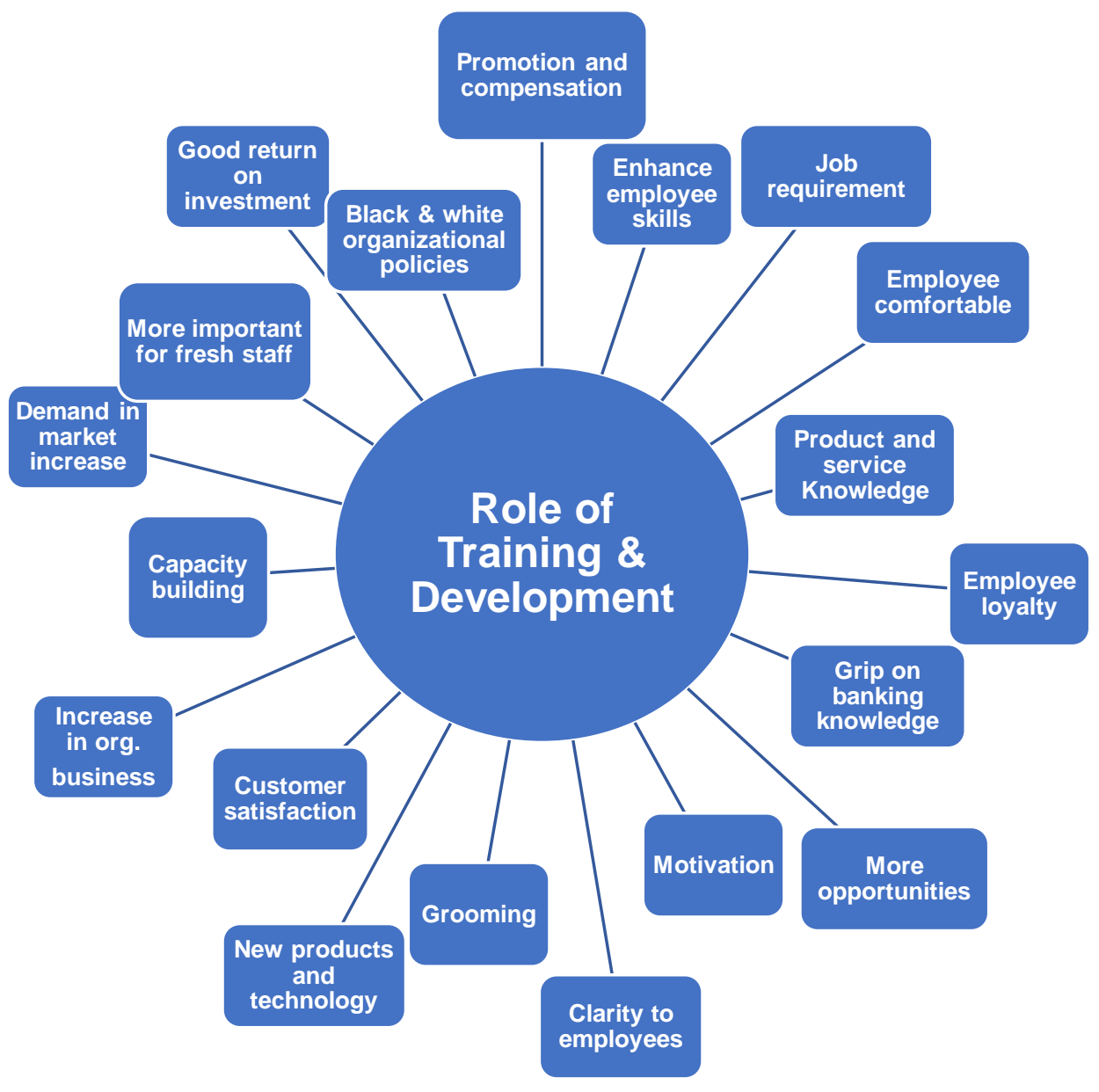

Figure 2: Important role of training \& Development

For long term retention of staff, compensation is one of the major factors. If the basic needs of the staff are not fulfilled after working more than 10 hours in the bank then the staff has a high turnover intention. The HR managers respond during the interview preceding that compensation is one of the major factors for staff retention. The staff working in the bank always compares the salary with the other colleagues performing the same duties in the same bank and other banks. If the staff feels that there is an inequity in the compensation then turnover intension of the staff is very high. The compensation structure of the bank is better than the other sector. It is concluded that the compensation system plays a very vital role in staff retention. The Important factor for the compensation system is shown in figure 3. 


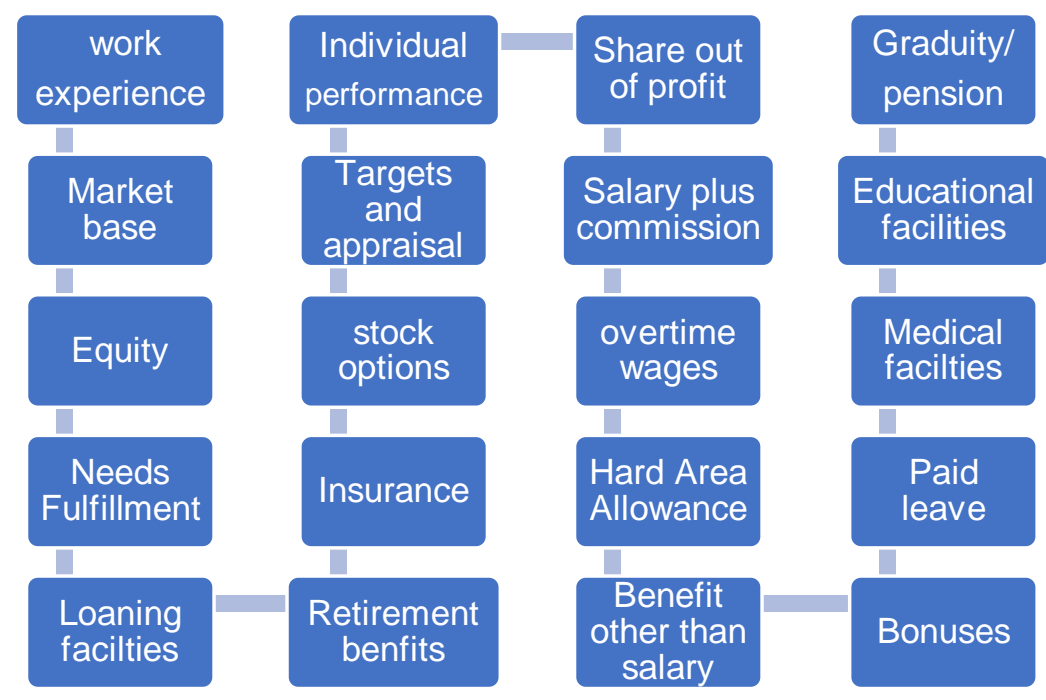

Figure 3: Important factor for compensation

As per the interview analysis of HR managers, it is observed that job security plays a very vibrant role in employee retention. The retention level of permanent staff is high as compare to contractual or third party staff. Job security is one of the very important factors for the higher retention rate in the public sector banks. Even the contractual employees feel secure in public sector banks as compare to other banks. The mangers state that the benefits of the permanent staff are more as parallel to contractual staff. The contractual employees will leave the bank if any new opportunity with little benefits is available to him but the permanent employee will serve for a longer period. It is concluded that job security plays a very important role in employee retention.

The managers of the banking sector respond that leadership practices play a very imperative role in staff retention. The respondents state that mostly, employee leaves the bank due to poor leadership practices. The leaders' behaviour, practices, relationship, style and attitude is very important for the employee and it is often said that people do not change job, people change boss. The leaders focus on staff monitoring, mentoring, coaching and counseling to keep them on track. The retention level will be high if the leader coordinates with the staff member and understands their issue and try to resolve them. The following are the major Leadership practices effecting employee turnover as shown in figure 4.

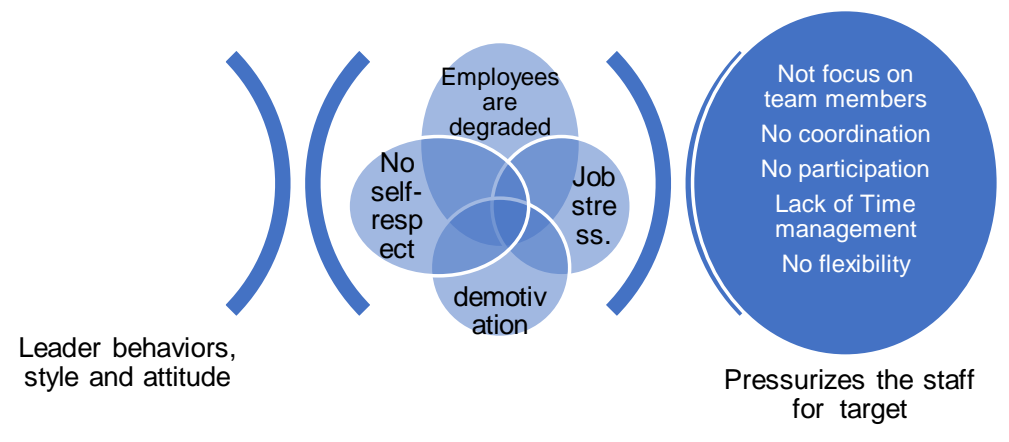

Figure 4: Leadership practices effecting employee turnover

The participants state that culture \& policy play a very vital role because the staff is attuned in a positive and flexible culture. The retention level is high in encouraging and positive culture and the retention rate is lower in case of poor and negative culture \& policies. The culture and policies of the public sector and foreign banks are very effective and employees oriented as compared to private and Islamic banks thus the retention rate of staff in public and foreign banks is higher as compared to private and Islamic banks based on this factor. 
HR managers respond that the banking environment has a substantial effect on staff retention. The managers state that the employee has to spend major time of life in two places, i.e. workplace and home. If the working environment of the place is caring, supportive and good, then the staff will remain in the firm for a long time as compared to a poor working environment. The staff can work in a poor culture but they cannot work in a poor and rigid working environment. The working environment of the public sector bank has also been improved over time. The HR manager of the foreign bank is of the view that the working environment of their bank is very effective and good which is helpful to enhance employee retention.

\section{Quantitative Analysis}

The finding of quantitative analysis is given below.

\subsection{Factor Analysis (FA)}

The factor analysis is performed to measure the factor loading and correlation among variables. There are several methods to extract the factors but in the current study Principal component method with varimax rotation is applied for measurement scales. The values are sorted by excluding a small coefficient by suppressing the value up to 0.40 . The principal component factor with varimax rotation extracted the 7 variables which explained the maximum variance. Some items factor loading value is less than 0.40 which is excluded from the pattern matrix. In the final rotated component factors matrix, 3 questions are deleted T5, WE1 and CP1. The following table 1 shows the factor loading of each item.

Table 1: Final Rotated Component Matrix

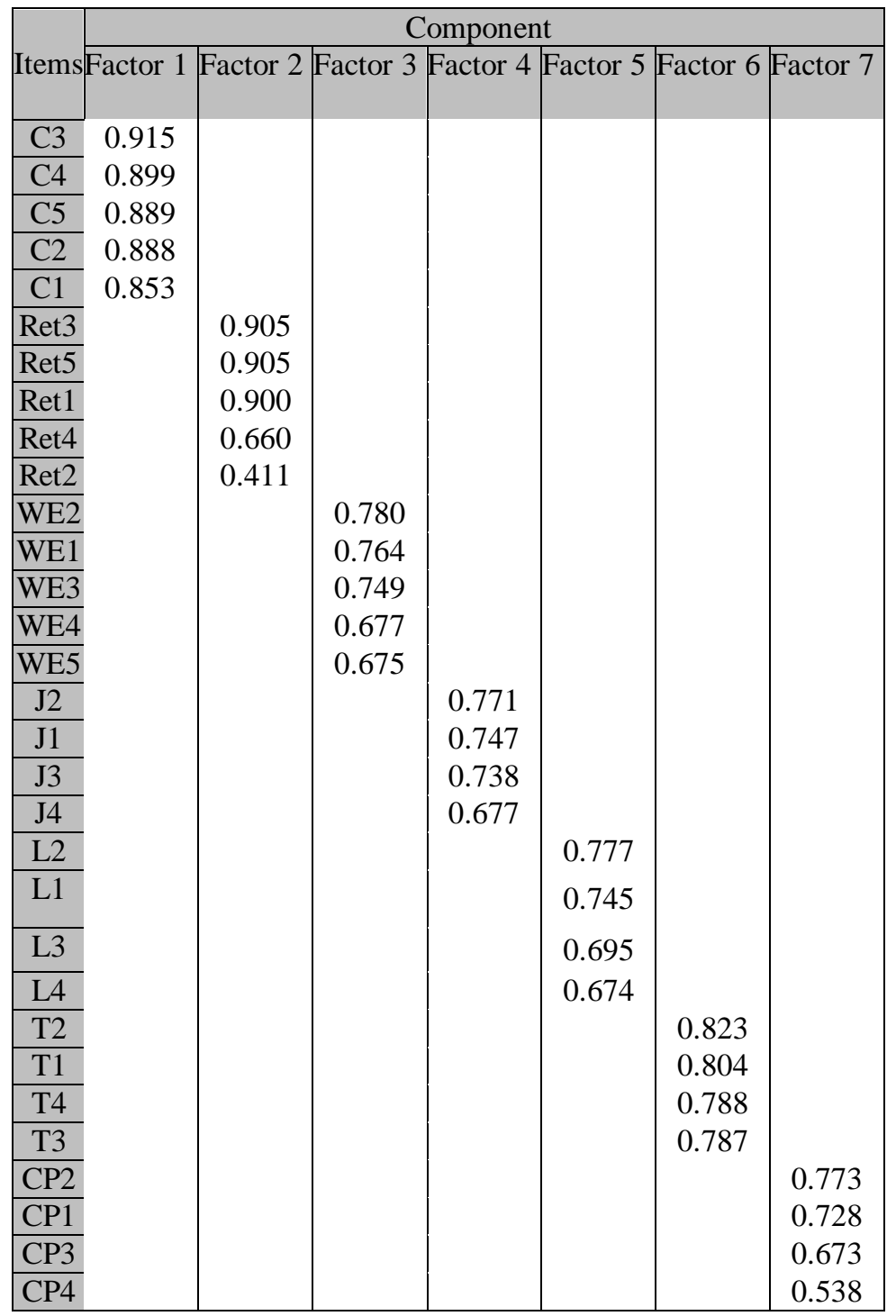




\subsection{Eigenvalue and Variance}

EFA is performed and Eigenvalue is greater than 1.0 explaining the cumulative variance of $68.466 \%$. The Eigenvalue of the extracted factors in this study ranged from 8.521 to 1.192 . Factor 1 compensation practices, is identified as the strongest factor because $\%$ of the variance is 8.521 . The following table explained the total variance of the components.

Table 2: Total variance explained.

\begin{tabular}{lrrr}
\hline Component & \multicolumn{3}{c}{ Eigenvalues } \\
\cline { 2 - 4 } 1 & \multicolumn{1}{c}{ Total } & \% of Variance & Cumulative \% \\
\cline { 2 - 4 } 2 & 8.521 & 27.488 & 27.488 \\
3 & 4.005 & 12.918 & 40.406 \\
4 & 2.694 & 8.690 & 49.096 \\
5 & 1.668 & 5.381 & 54.477 \\
6 & 1.656 & 5.343 & 59.820 \\
7 & 1.489 & 4.802 & 64.622 \\
\hline
\end{tabular}

\subsection{Kaiser-Meyer-olkin(KMO)}

The sample adequacy is sufficient because the value of KMO is greater than the cut off value 0.5 as anticipated by the Hair et al. (2010). The value of Bartlett's Test of Sphericity is significant which endorse that data is not identical. The following table 3 shows the value of KMO.

Table 3. KMO and Bartlett's Test

\begin{tabular}{llr}
\hline Kaiser-Meyer-Olkin Measure of Sampling Adequacy. & .880 \\
& Approx. Chi-Square & 8602.710 \\
Bartlett's Test of Sphericity & Df & 465 \\
& Sig. & .000 \\
\hline
\end{tabular}

\subsection{Collinearity Statistics}

The tolerance value and variance inflation factor (VIF)" is used to confirm whether there is any issue of multicollinearity in the model. The following table 4 clearly indicates that the tolerance value of each independent variable is greater than the cut point 0.2 and the value of VIF of each variable is less than cut point 5 , thus the researcher concluded that there is no chance of occurrence of multicollinearity in the model.

TABLE 4: Collinearity Statistics

\begin{tabular}{lcc}
\hline & \multicolumn{2}{c}{} \\
\cline { 2 - 3 } Training & Tolerance & VIF \\
\cline { 2 - 3 } compensation & .975 & 1.026 \\
Job security & .745 & 1.341 \\
Leadership & .785 & 1.273 \\
Working env & .586 & 1.707 \\
Culture \& policies & .653 & 1.530 \\
\hline
\end{tabular}

\subsection{Descriptive Statistics}

The following table 6 displays the descriptive statistics.

TABLE: 6 Descriptive Statistics

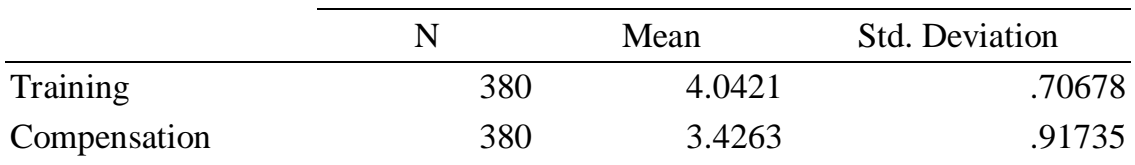




\begin{tabular}{lllr} 
Job security & 380 & 3.4095 & .97049 \\
Leadership & 380 & 3.7474 & .80196 \\
Working. Env & 380 & 3.6026 & .82985 \\
Culture \& policies & 380 & 2.4447 & 1.23690 \\
\hline
\end{tabular}

The mean score of training \& development, leadership and working environment near to four (agree stage) which means that the respondents are satisfied with these HR and organizational factors. The average score of compensation and job security is near to three (neutral stage). The mean score of culture \& policies is near to two (disagree stage) as per the questionnaire which means that the workforce is not satisfied with this variable.

\subsection{Correlation Analysis}

The following table 7 displays the correlations between the HR practices and employee retention.

\begin{tabular}{lrrrrrrr}
\hline \multicolumn{7}{c}{ Table 7: Correlations matrix } \\
\hline Ret & \multicolumn{1}{c}{ Ret } & \multicolumn{1}{c}{ Tra } & \multicolumn{1}{c}{ Com } & JS & Lead & WE & CP \\
Tra & $0.163^{* *}$ & 1 & & & & & \\
Com & $0.474^{* *}$ & -0.008 & 1 & & & & \\
JS & $0.392^{* *}$ & 0.066 & 0.078 & 1 & & & \\
Lead & $0.525^{* *}$ & $0.119^{*}$ & $0.466^{* *}$ & $0.297^{* *}$ & 1 & & \\
WE & $0.505^{* *}$ & 0.049 & $0.383^{* *}$ & $0.322^{* *}$ & $0.527^{* *}$ & 1 & \\
CP & 0.061 & -0.006 & 0.088 & 0.009 & 0.095 & 0.012 & 1 \\
\hline
\end{tabular}

The Training \& development has a substantial association with employee retention because correlation is $(0.165(* *)$, $* . p<.01)$. As per the above correlation matrix, there is a positive and significant association between compensation and employee retention. The value of beta correlation is $0.392(* *), . \mathrm{p}<.01$ which confirms that there is a positive relationship between employee retention and job security.

The results indicate that there is a positive relationship between leadership and employee retention because the value of $\mathrm{r}$ is $.525(* *), . \mathrm{p}<.01$. The working environment also has a significant and positive association with employee retention as per the above correlation matrix. Based on the value of $r$ which is 0.061 , it is concluded that culture \& policies have no significant association with employee retention.

\subsection{Regression Analysis}

The following table 8 specifies the outcomes of regression equation to find out the effect of HR practices on employee retention.

TABLE 8: Regression analysis of employee retention

\begin{tabular}{|c|c|c|c|c|}
\hline $\mathrm{R}$ & .643 & & & \\
\hline R Square & .413 & & & \\
\hline Adjusted R Square & .404 & & & \\
\hline Standard Error & .66270 & & & \\
\hline $\mathrm{F}$ & 43.745 & & & \\
\hline Sig. & .000 & & & \\
\hline Durbin Watson statistics & 1.634 & & & \\
\hline Independent Variable & Beta & t-value & & \\
\hline (Constant) & & & .480 & .631 \\
\hline Training & .115 & & 2.860 & .004 \\
\hline Compensation & 261 & & 5.688 & .000 \\
\hline Job security & .072 & & 1.740 & .083 \\
\hline Leadership & .239 & & 4.740 & .000 \\
\hline Working environment & .260 & & 5.413 & .000 \\
\hline Culture \& policies & .011 & & .273 & .785 \\
\hline
\end{tabular}


The above table of regression analysis clearly indicates that the independent variables explain $41 \%$ variation in the model. Our model is a good fit because the value of $\mathrm{F} 43.745$ which is significant at 0.000 .

As per the above table results, training \& development has a substantial and positive role in employee retention. The beta value of compensation is .261 as per regression analysis which is momentous at a $1 \%$ level of significance which indicates that this variable plays an imperative role to enhance employee retention. Job security does not affect employee retention as per regression analysis.

The results of the regression analysis specify that leadership practices have a substantial and positive role in employee retention. The working environment has a positive and substantial effect on staff retention in the banking sector. The culture and policies have no significant role with staff retention because mostly policies of this sector are customeroriented instead of employee-oriented.

\section{Discussion}

The training \& development activities are a regular feature in the banks to enhance knowledge, skills, experience and capacity building. This practice is being organized in the banks on a daily, monthly, quarterly and annual basis. The qualitative and quantitative results clearly indicate training \& development has a positive relationship and significant role on employee retention in the banking sector of Pakistan. However, there is a need for proper training need assessment and training should be arranged only for interested and core employees.

The compensation is one of the most vital factors to enhance staff retention. The compensation has a significant association and positive effect on employee retention as per qualitative and quantitative results. The employees working in developing countries like Pakistan are more interested and motivated with those HR practices which have indirectly or directly increase their earning capacity as compare to any other factor (Bashir \& Khattak, 2008).

Job security is an important factor as per qualitative analysis for staff retention. The contractual employee retention level is lower as compared to a permanent staff member because the contractual staff considers that their future is not secure due to poor job security. There is a positive affiliation between job security and employee retention as per the correlation matrix. However, as per the result of regression analysis, there is no substantial effect of job security on staff retention because the employees' jobs are not secure except in public sector banks. The staff working in the public sector bank has a high retention rate as compared to other banks. The reason for the non-significant effect is that more than $40 \%$ of staff included in the study are contractual or third party thus they have not happy and comfortable with job security. A column was left blank for additional information at the end of the questionnaires, wherein participants state that job security is one of the most crucial and important factors to retain them in the organization.

The leadership practices have a significant association with staff retention as per the qualitative analysis. It is correctly said by someone "the employees did not change the job but they did change their boss". The quantitative analysis also endorses the finding of qualitative analysis and concludes that leadership practices have a positive and significant effect on staff retention. The leader can develop such sort of environment which can encourage the staff to remain long term with the organization.

The qualitative analysis indicates that the working environment has a significant effect and role on employee retention. The quantitative results also endorse the results of qualitative results and find that employees are gratified with the working environment prevailing in this sector and it has a momentous relationship and role with employee retention.

The qualitative analysis concludes that positive culture and policies play a very important role in employee retention. The culture and policies of the banks were very attractive at the start of this sector but overtimes, due to targets, stress, increasing profits, timing and competition, the policies are customer oriented as compare staff oriented. The quantitative analysis clearly indicates that there is no substantial relationship and role between culture $\&$ policies and employee retention. It means that staffs are not satisfied with the existing culture and policies of the 
banking sector which is an indication of poor and weak cultures \& policies in the banking sector.

\section{Conclusion}

The banking sector is the mainstay of the economy but unfortunately, no comprehensive study is conducted to observe the role and association of human resource and organizational factors on employee retention in this sector of Pakistan. The organization should emphasis on such type of HR practices which are proficient to motivate, retain and satisfy the most critical assets, thus this study is very helpful to enhance staff retention in the banking sector of Pakistan. The major reasons for employee turnover are higher salary, better opportunity, relocation, personal reason, leadership, job security and working environment, etc.

HR and organizational factors play a very imperative role to enhance staff retention in the banking sector of Pakistan. The training \& development play a very significant relationship and role to improve employee retention, however, the training should be provided only to an energetic and interested person. The need assessment should also be made before training. The compensation practices also play a central role in staff retention because people are more interested and motivated with those practices which enhance their salary and allowances particularly in developing nations like Pakistan. Job security does not effect staff retention because they are not satisfied with job security except in the public sector banks. The leadership practices have a substantial role in employee retention because "the employees did not leave the organization but they leave their leaders "due to their attitudes, abusive language, behaviour and environment. The working environment also plays an imperative role in staff retention because the working environment is very comfortable as compared to other sectors. The employees are not satisfied with the culture and policies of the bank and therefore, this variable is no significant association and role with employee retention.

\section{Limitations and Future Study}

The limitations of the current study are that it has a small sample size and to generalize the findings, the sample should be large. This study is carried out in the banking sector and in the future, the study should be carried out in other sectors of Pakistan to test this model. In the future, some other HR practices should be considered to increase employee retention, i.e. job rotation, performance appraisal, recognition, politics and challenging assignments, etc. In the future, the demographical, variables should also be considered for analysis.

\section{References}

Abeysekera, R. (2007). "The impact of human resource management practices on marketing executive turnover of leasing companies in Sri Lanka." Contemporary Management Research 3(3).

Alzayed, M. and M. A. Murshid (2017). "Factors Influencing Employees' Intention to Leave Current Employment in the Ministry of Information in Kuwait." organization 10(01).

Ashraf, M. A. and R. MHR Joarder (2012). "Human Resource Retention Practices From The Employees' Perspective." International Research Journal Of Business Studies 1(2).

Azeez, S. A. (2017). "The impact of appraisal system, supervisor support and motivation on employee retention: A review of Literature." International Journal of Commerce and Management Research, Issn-2455-1627 3.

Bashir S, \& Khattak HR (2008). Impact of selected HR practices on perceived employee performance, a study of Public Sector Employees in Pakistan.European Journal of Social Sciences. 5(4), 243-252.

Chew, J. C. L. (2004). The influence of Human Resource Management practices

on the retention of core employees of Australian organizations : An

empirical study. Murdoch University, Perth, Western Australia.

Chia, S. L., Y. V. Lee, et al. (2014). The factors impact on employee retention in semiconductor industry, UTAR.

Dei Mensah, R. (2014). Effects of human resource management practices on retention of employees in the banking industry in Accra, Ghana.

DiPietro, R. B. and A. Milman (2004). "Hourly employee retention factors in the quick service restaurant industry." International journal of hospitality \& tourism administration 5(4): 31-51.

Geo rge, J., \& Jones, G. (2008). Understanding and Managing Organizational Behavior (5th edition) Upper Saddle River, New Jersey: Pearson Prentice Hall

Irshad M. (2009). Factors affecting employee retention, Abasyn journal of social science. Vol. 4No. 1 
Jane Mucheke Ng'ethe (2013) Determinants of Academic Staff Retention in Public Universities in Kenya. Jomo Kenyatta University Of Agriculture And Technology

Kochachathu, P. (2010). Influence of Human Resource Practices on Employee Retention.Masters Thesis, University of Malaysia.

Milne, P. (2007), "Motivation, incentives and organizational culture”, Journal of Knowledge Management,11,6:2838.

Muhsin Bilal, Miss Muqdas Rehman, Chaudhary Abdul Rehman. Causes of Employee turnover in banking sector of Pakistan. Researcher 2015;7(7):73-82]. (ISSN: 1553-9865). http://www.sciencepub.net/researcher. 13.

Neog, B. B., \& Barua, M. (2015). Factors Affecting Employee's Retention in Automobile Service Workshops of Assam: An Empirical Study. The SIJ Transactions on Industrial, Finance \& Business Management (IFBM), 3(1), 9-18.

Nwokocha, I. and E. Iheriohanma (2015). "Nexus between leadership styles, employee retention and performance in organizations in Nigeria." European Scientific Journal, ESJ 11(13).

Paille, P. Grima, F. and Bernardeau, D., (2013) 'When Subordinates Feel Supported by Managers: Investigating the Relationships between Support, Trust, Commitment, and Outcomes.' International Review of Administrative Sciences, 79(4):pp.681-700.

Samuel, M. O. and Chipunza, C. (2009). Employee retention and turnover : Using

motivational variables as a panacea. African Journal of Business

Management, 3 (8), p.410-415.

Shahid, A. (2017). Strategies Used by Banking Managers to Reduce Employee Turnover, Walden University.

Shoaib, M., Noor A., Tirmizi, S., \& Bashir, S. (2009). Determinants of Employee Retention in Telecom Sector of Pakistan. Proceedings 2nd CBRC, Lahore, Pakistan, 14th November 2009.

Stavrou-Costea, E. (2005). "The challenges of human resource management towards organizational effectiveness: A comparative study in Southern EU." Journal of European industrial training 29(2): 112-134.

Taylor, C. (2004). Modern social imaginaries, Duke University Press.

Waleed, A., (2011). The Relationship between Human Resource Practices and Employee Retention in Public Organisations. An Exploratory Study Conducted in the United Arab Emirates. Ph.D. Thesis, Edith Cowan University.

Winterton, J. (2011). A conceptual Model of Labour Turnover and Retention. Human Resource Development International, 7(3), 456-459.

Zhao, H., Wayne, S. J., Glibkowski, B. C., \& Bravo, J. (2007). The impact of PC breach on work-related outcomes: A Meta-analysis. Personnel Psychology, 60, 647 